\title{
ARTIGO
}

\section{COMPLEMENTARIDADE QUALITATIVO-QUANTITATIVA NA PESQUISA EM INFORMAÇÃO}

\section{QUALITATIVE-QUANTITATIVE COMPLEMENTARIENESS IN INFORMATION RESEARCH}

Leilah Santiago BUFREM*

\author{
RESUMO
}

Analisa como a discussão sobre a conduta investigativa foi estimulada a partir do séc. XVII pelos êxitos da experiência como fonte de conhecimento. Métodos quantitativos ganham espaço nas áreas humanas e sociais. Atualmente, outros enfoques alternam-se ao paradigma positivista. Permanecem, entretanto, antagonismos entre enfoques quantitativos e qualitativos, simultaneamente a formas de rearticulação interdisciplinar. Da mudança qualitativa na prática da pesquisa social resultam opções à contradição entre os enfoques. A possibilidade de integrá-los na construção de conhecimentos é concretizada com estratégias múltiplas, dada a interdependência entre desenvolvimento cientifico, mudanças no contexto e criatividade na investigação.

Palavras-chave: Pesquisa em informação; Métodos qualitativos; Métodos quantitativos.

\section{ABSTRACT}

Discussion about investigative methods has been stimulated since the XVII century due to quality of knowledge generated with successful experimentation. Inductive reasoning started to be used in human and social sciences. In the recent past, alternative methods were used as options to positivism. While there are some antagonisms between quantitative and qualitative methodologies, interdisciplinary efforts offer qualitative changes to methodological approaches. Quantitative research does not necessarily represent a counterpoint to qualitative one. Integration between the two interpretations can be realized with the use of multiple strategies. Hence, there is a possibility to understand methodology as an integrated view of problems and alternative solutions.

Key-words: information research, qualitative method, quantitative method.

\section{INTRODUÇÃO}

O propósito de analisar indícios de complementaridade entre aspectos qualitativos e quantitativos na pesquisa com métodos múltiplos compatibiliza-se, neste trabalho, com a tentativa de relativizar antinomias ou oposições entre o que se considera atitude científca ou não-científica,

(•) Profa. Titular Dra. do Departamento de Ciência c Gestão da Informação da Universidade Federal do Paraná. 
objetividade ou subjetividade na pesquisa em ciências humanas. Com esse intento, colocam-se inicialmente as diferenças entre as duas visões dominantes na pesquisa para caracterizá-las e somente então sugerir a complementaridade possivel.

Aceita-se que qualquer trabalho científco, desenvolvido em determinado contexto social e em dado momento histórico, reflete as mudanças e contradições desse contexto, tanto em sua organização interna ou método, quanto em suas aplicações. Se por método, segundo o sentido etimológico que remonta a Platão, se deve entender o encaminhamento dado à investigação, esse encaminhamento pode resultar de opções ou perspectivas como as que se definem entre o tratamento quantitativo e o qualitativo, em decorrência do peso específico e representativo de cada um para a pesquisa em questão.

Assim, as forças denominadas por CHALMERS de progressistas, estimuladas, a partir do séc. XVII pelos êxitos de grandes cientistas, passaram a considerar cada vez mais a experiência como fonte de conhecimentos (1991, p. 11). Os impactos promovidos pelos sucessos dos métodos das ciências físicas sobre o mundo moderno, decorrentes dos avanços científicos, influenciaram amplamente e com expressiva repercussão a condução teórica e prática das pesquisas subseqüentes.

A partir de então, o prestígio da pesquisa experimental aumenta consideravelmente, a ponto de se afirmar que a ciência seria uma estrutura assentada sobre fatos. A trajetória do pensamento para alcançar a verdade, fundada na experiência, passa a ser apreciada como método por excelência para as ciências naturais.

Surge, assim, o conceito moderno de pensamento científco, marcado pelo desenvolvimento das ciências naquele século e criando expectativas de que os conhecimentos gerados pelas ciências humanas e sociais permitiriam ao homem um domínio análogo sobre o mundo humano e histórico. Enfatizada a importância da experimentação e da possibilidade de quantificá-la, esses procedimentos passam a ser propostos como métodos também para as ciências humanas.

A polêmica instaurada pela aceitação ou não desse paradigma dominante ocorre mais precisamente a partir do advento do positivismo, termo cunhado por Augusto Comte para definir uma forma de empirismo estrito, apresentada historicamente como teoria geral da ciência, ao mesmo tempo uma concepção global do devir do espírito humano. Esta teoria foi objeto do seu Curso de Filosofia Positiva, publicado em Paris, em seis volumes, entre 1830 e 1842, após exposição a um público selecionado entre cientistas, em busca de uma nova visão geral do conhecimento e da sociedade. Segundo Comte, a ordem seria a base do conhecimento científico e só teriam caráter de legitimidade as pretensões de conhecimento fundadas na experiência. Assim como Augusto Comte, Stuart Mill e Durkheim foram defensores da tese da unidade das ciências, que legitimaria o argumento a favor da utilização do mesmo método para todas as ciências, sejam sociais, físicas ou naturais.

Observando que o tema foi desenvolvido pelos neopositivistas nas décadas de 1920 e 1930, GRANGER avalia ter sido tão forte o seu sentido a ponto de compreender uma uniforme estruturação lógicomatemática do conhecimento científico e a possibilidade de expressão dos conteúdos empíricos, em linguagem única, independentemente da área. Essa concepção leva-o a se perguntar sobre a unidade real da ciência. Ao mesmo tempo em que relativiza essa unidade da ciência, o autor faz justiça à pluralidade de métodos $e$ de objetos associada à unidade de uma comum visão do conhecimento (1994, p. 42).

Percebe-se nesse continuum que Teixeira COELHO denomina de projeto da modernidade, lançado no século XVIII e afirmado ao longo do XIX, processos como o da Revolução Industrial, de um novo pensamento sobre o social (como o de Karl Marx) e dos passos iniciais da psicanálise, para ficar nos mais evidentes. Transformações mais radicais ocorreriam após 1905, ano da teoria que viria a alterar o núcleo do conhecimento humano, quando Einstein revisa em seus artigos revolucionários sobre a relatividade conceitos fundamentais para o homem, como o de espaço e tempo. Deixam de existir noções até então consideradas postulados, principios não demonstrados...(1995, p. 25).

Progressivamente, passam a ser consideradas também possibilidades metodológicas cujos critérios de objetividade não seriam dependentes apenas de considerações quantitativas ou de modelos irrefutáveis.

\section{AS VISŌES DOMINANTES NA CONDUÇĀO DAS PESQUISAS}

Constata-se que a partir dos últimos trinta anos a oposição entre os chamados paradigmas quantitativo e qualitativo predomina nas discussões sobre as pesquisas em ciências sociais. Das tentativas de superar controvérsias entre adeptos ou não dessas posições, decorrentes especialmente da interpretação positivista dos fenômenos sociais, alternam-se correntes caracterizadas por diferentes abordagens. Essa 
tendência talvez se deva ao fato, como afirmou GADAMER, de que se espera ainda mais das ciências do espírito ao se perceber que o crescente domínio da natureza acrescenta o mal estar na cultura ao invés de reduzi-lo (1994, p. 43).

A crítica de FEYERABEND aos empiristas expressa a restrição que esta corrente faz à variedade, cunhada pela condição de coerência, e que se traduz pela denominada adoração dos fatos, traço característico de todo empirismo (1989, p. 57). Ao ressaltar a multiplicidade dos métodos, as lacunas das explicações científicas e a precariedade das teorias, o próprio filósofo não se considera um anarquista sério e, segundo GRANGER, o aspecto positivo de sua epistemologia consiste na violenta crítica ao conservadorismo e ao dogmatismo, sublinhando a mobilidade do conhecimento científico (1994, p. 43).

Quanto a POPPER, um dos mais incisivos representantes da crítica ao indutivismo, ao lançar as bases do método hipotético dedutivo e do critério de falseabilidade, na sua obra Conjectural knowledge: my solution to the problem, assume a posição de realista crítico ao acreditar que um mundo material existe, independente da experiência. Por outro lado, pode-se identificar, pela postura metodológica que adota enunciar claramente o problema e examinar, criticamente, as várias soluções propostas (1975, $\mathrm{p}$. 536) - que ele relaciona a atitude científica a uma postura racional e crítica diante dos problemas. Essa postura expressa-se no método hipotético-dedutivo, que consiste na construção de conjecturas a submeter aos testes mais diversos, à crítica intersubjetiva, ao controle mútuo pela discussão, à publicidade crítica e ao confronto com os fatos para a verificação das hipóteses que se sustentam como mais aptas por resistirem às tentativas de refutação e falseamento. A importância do critério de falseabilidade tem sido reconhecida e interpretada especialmente por estar ligada à idéia de um conhecimento que se cria e se constrói, critério que corresponde ao aspecto dinâmico do saber.

No esforço para instaurar uma verdadeira ciência do homem, Lévi-Strauss distingue com o estruturalismo três níveis de investigação: o da etnologia, o da etnografia e o da antropologia. O da etnologia corresponde ao primeiro passo para chegar, passando pelo nível da etnografia, à síntese representada pelo da antropologia, em que se pode adquirir um conhecimento global do homem, abrangendo seu tema em toda a extensão histórica e geográfica.

Hoje, o estruturalismo estende-se a todo o domínio das ciências humanas, concretizando-se em oposição ao empirismo já que nega significado ao fato isolado como tal. Por outro lado, o estruturalismo também se opõe a qualquer tipo de idealismo pois, embora seu modelo conceitual se apresente como uma construção científica, ele não poderia ser reduzido a um ato ou função subjetiva. Dessa forma, segundo FOUGEYROLLAS, (1992,p. 90), confirma a objetividade de todo sistema de relações.

Com destaque pelo importante papel que desempenhou para a evolução da pesquisa qualitativa nas ciências sociais, a fenomenologia de Husserl tem sido considerada uma linha de pensamento cuja principal contribuição para a epistemologia consiste na ampliação das opções metodológicas, frente ao domínio positivista sobre as ciências sociais. Husserl apresentou o método fenomenológico como um modo seguro e liberto de pressuposições para todas as ciências. A fonte de conhecimento seria a consciência. Assim, toma como ponto de partida de sua filosofia e da metodologia dela decorrente os fenômenos da consciência, por entender que somente eles poderão revelar o que as coisas realmente são. A intencionalidade, como característica da consciência e conceito chave da fenomenologia, é utilizada por Husserl de modo bastante preciso para indicar que a consciência é sempre consciência de alguma coisa. Daí que seu método consiste na visão intelectual do objeto, a partir de uma intuição. A intuição dirige-se ao fenômeno (ao dado) e nenhuma categoria deve interpor-se entre os dois. Essa exigência requer uma tríplice eliminação ou redução: do subjetivo, ou posturas diante do dado (fenômeno); do teórico, presente em hipóteses, pressupostos ou saber adquirido e de toda tradição, ou seja de tudo o que foi dito sobre o fenômeno. A intuição eidética, ou intuição da essência, é portanto dirigida para as coisas mesmas e orientada para o dado, com exclusão de todo o subjetivo e de tudo o que já se tenha dito sobre ele. Alguns nomes como os de Merleau-Ponty, Paul Ricoeur, Karl Jaspers, L. Binswanger e Paul Tillich receberam sua influência, segundo SUTTON, em parte ao desenvolvimento de métodos que a fenomenologia inspirou diante das perceptíveis limitações nos estudos sociológicos e em parte pela similaridade dos fenômenos estudados (1993, p. 415).

Outra linha de inegável valor para a epistemologia foi o pensamento dialético. Com lançamento talvez exagerado, quase num manifesto, como afirma GOLDMANN, converteu-se na proclamação da mudança radical que se opera no pensamento filosófico. Ao Ego de Montaigne e Descartes, Pascal responde: $O$ eu é odioso. A partir de entã́o, de Hegel $\mathrm{a}$ Marx, os outros homens tornam-se cada vez mais seres agindo em comum (1958, p. 14). Dessa forma, o nós prevalecerá entre os 
dialéticos, convertendo-se em realidade fundamental da qual o eu será derivado. A análise dialética define as relações do geral com o particular em sua concretização histórica. Como metodologia stritco sensu representa um esforço epistemológico que procura destacar os traços comuns ou, ao contrário, diferenciados de um caso para outro, de todas as abordagens científicas que visam prestar contas dos processos que se desenrolam no tempo.

Para o pensador dialético, as doutrinas fazem parte integrante do fato social em si, somente separáveis dele por uma abstração provisória. Seu estudo é um elemento indispensável do estudo atual do problema, da mesma forma que a realidade social e histórica constitui um dos elementos mais importantes quando se trata de comprender a vida espiritual de uma época (GOLDMANN, 1958, p. 47). O pensamento dialético, ao acentuar o caráter total da vida social, visa a contribuir para a unidade do pensamento e da ação. Como principal instrumento do pensamento científico em ciências humanas, destaca-se a consciência possível. Esta, em grau máximo, expressa possibilidades no plano do pensamento e da ação em uma determinada estrutura social.

\section{O LABIRINTO: UMA ANALOGIA ANTI-DICOTÔMICA}

Como se observa na literatura que sustenta a discussão, é possível analisar as diferenças fundamentais entre as duas abordagens, tanto em relação aos pressupostos epistemológicos quanto aos procedimentos metodológicos da pesquisa. É também viável cotejar procedimentos, independentemente dos pressupostos teóricos e princípios filosófcos que os orientem, como se apresenta, ainda, a possibilidade de conciliar as posições antagônicas argumentando-se pela compatibilidade e cooperação mútua entre os paradigmas. Isso porque há na multiplicidade de estratégias metodológicas uma fonte inesgotável e rica para a prática da pesquisa, especialmente a partir das tentativas de superação da antinomia entre os enfoques qualitativo e quantitativo na sua condução.

Refletindo especificamente sobre a polêmica entre esses enfoques, HABERMAS observa que, metodologicamente falando, a medida desempenha duas funções: a de garantir a simplificação de controvérsias sobre as questões existenciais e a de possibilitar repetição, permitindo assim a garantia de intersubjetividade da experiência (1994, p. 96). O debate tem sido motivado, entre outros aspectos, pelos níveis e categorias de estudo que apresenta. São discutidos especialmente os princípios filosóficos - ontológicos, epistemológicos e axiológicos - que envolvem a oposição entre os paradigmas qualitativos e quantitativos.

A análise desenvolvida por CRESWELL ilustra essa preocupação ao acrescentar aos enfoques ontológico, epistemológico e axiológico, o retórico e o metodológico como pressupostos para diferenciação dos paradigmas. Assim, à questão sobre a natureza da realidade, o paradigma quantitativo a entende como objetiva e singular, distinta do pesquisador, enquanto o qualitativo a define como subjetiva e múltipla, decorrente da diversidade de interpretações dos participantes de um estudo.

Do ponto de vista epistemológico, questiona-se sobre o relacionamento do pesquisador com o pesquisado, ao que o paradigma quantitativo responde que o primeiro é independente do segundo, enquanto o qualitativo defende a interação entre o pesquisador e aquilo que está sendo pesquisado.

Sob o enfoque axiológico, isto é, com relação ao papel dos valores na busca do conhecimento, costumase afirmar que na condução quantitativa da pesquisa eles não têm lugar, enquanto a investigação qualitativa é carregada de valores e preconceitos.

Quanto à suposição retórica, isto é, relativa à linguagem da pesquisa, costuma-se afirmar que nos tratamentos quantitativos a expressão é formal, baseada em definições fixadas, voz impessoal, uso de termos quantificáveis e convencionados, em oposição à linguagem informal, característica do enfoque qualitativo,que implica decisões, tem voz pessoal e palavras não-convencionadas.

Ao argumentar contra a dicotomia amplamente aceita entre os paradigmas quantitativo e qualitativo, HAMMERSLEY aponta para seu uso limitado e discorre sobre alguns perigos dela decorrentes, especialmente por obscurecer questões e argumentos que envolvem a metodologia das ciências sociais. Identificando os componentes mais relevantes da distinção entre qualitativo e quantitativo, especialmente pelos defensores da pesquisa qualitativa, o autor argumenta que as questões colocadas não são simples como aparentam (1992, p.160).

Ele apresenta e discute sete questões relacionadas aos critérios que orientam a distinção qualitativo-quantitativa: utilização de palavras preferencialmente a números; ocorrência do fenômeno em circunstâncias naturais ou criadas pelo pesquisador; foco no significado em oposição ao foco no comportamento; utilização da ciência natural como 
modelo; abordagem indutiva versus dedutiva; identificação de padrões culturais versus busca de leis científicas e idealismo versus realismo.

Em relação ao uso de palavras de preferência aos números, mais precisamente sobre a preferência dos dados qualitativos em oposição aos quantitativos, o autor argumenta que ao pesquisador caberá julgar entre uma série de dados mais ou menos precisos, para decidir sobre o nível de precisão apropriado em relação a uma exigência particular. Essa decisão estaria, portanto, na dependência da natureza do que se pretende descrever, na desejável precisão das descrições, nos propósitos e nos recursos disponíveis. Com esse argumento ele descarta o compromisso ideológico com ou outro enfoque paradigmático.

A segunda distinção apontada pelo autor, sobre a natureza do fenômeno observado, identifica as pesquisas experimentais com as situações previamente estabelecidas, por meio das quais se deseja aquilatar diferentes valores relativos a variáveis a controlar. Por outro lado, as pesquisas etnográficas requerem o estudo de situações que poderiam ocorrer sem a presença do pesquisador, ou com a adoção de uma postura que minimize o impacto do pesquisador sobre a ocorrência. Sob o ponto de vista do autor, a distinção é espúria pois os termos natural e artificial vêm perdendo suas conotações originais, diante do espectro de possibilidades de pesquisas e observações mais ou menos controladas.

Quanto à distinção entre a focalização no significado ou no comportamento, tem sido relacionada com a ênfase no caráter interpretativo ou hermenêutico da pesquisa qualitativa, em contraste com o ponto de vista comportamentalista quantitativo. Com efeito, a pesquisa qualitativa busca compreender a perspectiva das pessoas, entretanto, nem sempre restringe seu foco de modo restrito a elas, pois em geral o comportamento não é apenas um subproduto das perspectivas, e até pode delas discrepar. Por outro lado, há pesquisas quantitativas mais voltadas a atitudes do que propriamente a comportamentos.

$O$ enfoque quantitativo também tem sido identificado com o modelo da ciência natural. Entretanto, essa simplificação é discutível, primeiramente pelas diferenças possiveis entre as diversas ciências da natureza, ou disciplinas delas decorrentes. Pode-se também questionar que interpretação se irá adotar. E, ainda, deve-se esclarecer que nenhum método das ciências naturais pode ser adotado sob medida para as ciências humanas.
É comum, também, estabelecer a aproximação da pesquisa qualitativa com o método indutivo, em contraposição com a identidade entre pesquisa quantitativa e método hipotético dedutivo. Quanto a esse aspecto, qualquer simplificação é precária pois toda pesquisa envolve tanto dedução quanto indução uma vez que o pensamento move-se de idéias para dados e de dados para idéias.

A identificação de padrões culturais nas pesquisas qualitativas, em oposição à procura de leis científicas como propósito das pesquisas de enfoque quantitativo, é outra distinção em pauta quando se tenta contrapor os dois enfoques. Entretanto, nem sempre as pesquisas quantitativas vão além de generalizações probabilísticas, enquanto que muitas vezes os objetivos das pesquisas qualitativas visam o estabelecimento de teorias.

Quanto às posições epistemológicas dos enfoque de pesquisa, costuma-se identificar o qualitativo com a idealista e o quantitativo com a realista, resultando numa dicotomia não correspondente com as questões que têm sido colocadas por representantes das duas posições. Esta constatação esclarece a posição de HAMMERSLEY para quem na epistemologia, assim como na metodologia, as dicotomias relativizam o alcance das opções abertas (1992, p.171).

Ao concluir suas considerações sobre o tema, enfatizando que a seleção entre as duas posições depende dos propósitos e circunstâncias da pesquisa, o autor cria uma nova analogia. Substituindo a idéia que representa um cruzamento onde se deve optar pela esquerda ou pela direita, apresenta a imagem do labirinto, diante do qual o pesquisador depara-se constantemente com a necessidade de tomar decisões menos definitivas ou rígidas do que de outro modo poderiam ser.

Essa leitura e entendimento coincidem com conclusões de estudo anterior em que, ao analisar um recorte expressivo da literatura resultante da pesquisa em ciência da informação no Brasil, nota-se que

à medida em que cada campo de atividade científica vai se fortalecendo e conquistando autonomia, as estratégias metodológicas, as técnicas e os instrumentos selecionados pelos pesquisadores vão se tornando cada vez mais complexos em suas combinações e menos puros em relação as suas formas originais de concepção. Mas isso deveria ser observado e aceito como uma prática viva de fazer pesquisa e não como uma quebra da ortodoxia metodológica (BUFREM,1996,p.145). 
A pesquisa e o seu aperfeiçoamento, portanto, além de desafios, são motivações para que acadêmicos e profissionais tomem consciência da necessidade de superar as oposições presentes na discussão qualitativoquantitativa, ampliando sua compreensão a respeito das possibilidades teóricas e concretas ao seu alcance e subsidiando a avaliação de sua prática.

\section{CONSIDERAÇÕES FINAIS}

A insistência nos círculos acadêmicos em contrapor de modo dicotômico os enfoques qualitativo e quantitativo em relação às trajetórias metodológicas possíveis nas ciências sociais deve ser superada, especialmente nas ciências da informação, cujo caráter interdisciplinar permite uma postura mais inclinada à diversidade de enfoques na pesquisa científica.

Se retomados os critérios de CRESWELL para diferenciar os enfoques quantitativo e qualitativo em relação à questão da natureza da realidade, a forma de superá-la com abordagens múltiplas admite a natureza objetiva e singular do real, sem descartar o exercício da subjetividade e a natureza múltipla dos seus desdobramentos concretos, passíveis de interpretação do pesquisador e demais participantes de um estudo.

Sob o aspecto epistemológico, mais precisamente voltado à relação entre pesquisador e pesquisado, as abordagens múltiplas ensejam a interação entre ambos, descartando-se a idéia do predomínio de um sobre outro.

Quanto ao papel dos valores na pesquisa, isto é, do ponto de vista axiológico, a complementaridade quantitativo-qualitativa transcende o maniqueismo entre, por um lado, uma atitude totalmente liberta de valores como critério para obtenção da verdade e, por outro, uma situação de busca do conhecimento subjugada por escolhas ideológicas ou valorativas.

Em relação à suposição retórica, isto é, à linguagem da pesquisa, o modo de superar o dualismo quantitativo-qualitativo afasta-se da rigidez formal como linguagem única para aceitar, em circunstâncias que a favoreçam, uma voz mais pessoal que envolva decisões entre a afirmação absolutamente categórica e as nuanças possiveis em espectros mais amplos de opções semânticas.

Infere-se do exposto que formas tradicionais de fazer pesquisa, como exercício de enfoque hegemônico, rigidamente quantitativo ou estritamente antiquantitativo, acabam por condicionar as trajetórias e resultados dos estudos, tornando-se modelos superados para as ciências sociais. Por outro lado, a criação de múltiplas formas de realização de estudos nessas áreas sugere possibilidade e motivação para metodologias mais criativas, ensejando que pesquisadores entreguem-se à tarefa de renovação de suas práticas de modo a atender expectativas de construções mais adequadas às possibilidades teóricas e empíricas ao seu alcance.

Assim, ao pesquisar sobre informação, tanto as questões consideradas conceituais, quanto aquelas orientadas à prática, é possível construir trajetórias selecionadas dentre as amplas possibilidades que cada um dos campos da ciência oferece concretamente.

Acompanhando esse processo de discussão lógica e epistemológica, observado na literatura analisada, percebe-se a metodologia aceita como disciplina filosófica apenas relativamente autônoma pois destina-se à análise das técnicas de pesquisa empregadas em uma ou mais ciências. As questões mais evidenciadas não se referem apenas às distinções entre os paradigmas qualitatito ou quantitativo, mas de modo especial às possibilidades de complementação, especialmente recorrendo-se à utilização de metodologias múltiplas, consideradas em suas estruturas específicas e nas condições que tornam possível a sua concretização.

\section{REFERÊNCIAS}

ALEMNA, A; BADU, E.. The nature and trends in research and journal literature in english speaking Africa. International Information and Library Review, v. 26, p. 19-30, 1994.

BRADLEY, J. Metodological issues and practices in qualitative research. Library Quaterly, Chicago, v. 63, n. 4, p. 431-449. 1993.

BREWER, J.; HUNTER, A. Multimethod research: a synthesis of styles. California: Sage, 1989. 209 p. (Sage library of social research,175).

BUFREM, L. S. Linhas e tendências metodológicas na produção discente do Mestrado em Ciência da Informação do Instituto Brasileiro de Informação em Ciência e Tecnologia - Universidade Federal do Rio de Janeiro (19721995). Curitiba,1996. 386 f. Tese (Professor Titular) Departamento de Biblioteconomia, Setor de Ciências Humanas, Letras e Artes, Universidade Federal do Paraná.

CARR, D. Qualitative Meaning in cultural institutions. Journal of Education for Library and Information Science, $\mathrm{v}$. 31, n. 2, p. 97, 1990.

CHALMERS, Alan. ¿Qué es esa cosa llamada ciencia? : una valorización de la naturaleza y el estatuto de la ciencia y sus métodos. 9. ed. Madrid: Siglo Veintiuno,1991. 246 p. 
CHRÉTIEN, Claude. A ciência em ação: mitos e limites. Campinas: Papirus, 1994.

COELHO NETTO, J. T.. Moderno pós moderno: modos \& versões. 3. ed. São Paulo: Iluminuras, 1995. 227 p.

COOPER, M. Perspectives on qualitative research with quantitative implications: studies in information management. Journal of Education for Library and Information Science, v. 31, n.2, p.105-112, 1990.

CRESWELL, J. W. Research design: qualitative and quantitative approches. Thousend Oaks: SAGE, 1994. 227 p.

DESCARTES, R. Discurso sobre o método. São Paulo: Hemus, 1968. 100 p.

FEYERABEND, P. Adeus à razão. Lisboa: Edições 70, 1991. 372 p. (Biblioteca de filosofia contemporânea, 14).

. Contra o método. 3. ed. Rio de Janeiro:

F. Alves, 1989. 488 p.

FOUGEYROLLAS, P. Ciencias Sociales y Marxismo. México: Fondo de Cultura Económica,1992. 253 p.

FOX, D. Techniques for the analysis of qualitative data. In: $\quad$ The research process in education. New York: Holt, Rinehart and Winston,1969. p. 646-679.

GADAMER, H.-G. Verdad y método II. 2. ed. Salamanca: Ediciones Sígueme, 1994. 429 p. (Hermeneia, 34).

GOLDMANN, L. Las ciencias humanas y la filosofia. Buenos Aires: Galatea Nueva Vision,1958. 120 p.

GRANGER, G.-G. A ciência e as ciências. São Paulo: Ed. da UNESP, 1994. 122 p.

HABERMAS, J. On the logic of the social sciences. Cambridge: Massachusetts Institute of Technology,1994. 220 p.

Técnica e ciência como "ideologia". Lisboa : Edições 70, 1994. 147 p.

HAMMERSLEY, M. What's wrong with ethnography? Methodological explorations. London: Routledge,1992. 230 p. .

HANNABUSS, Stuart. Approaches to research. Aslib Proceedings, London, v. 47, n. 1, p. 3-11, jan. 1995.

HARICOMBE, L. J. Combining qualitative and quantitative methodologies to study the effects of an academic boycott on academics in South A frica. Library Quaterly, Chicago, v. 63, n. 4 , p. $508-527,1993$.

IBÁÑEZ, J. Del algoritmo al sujeto: perspectivas de la investigación social. Madrid: Siglo Veintiuno de España, 1985. $365 \mathrm{p}$.

JENSEN, K. B.; JANKOWSKI, N. W. (Eds.). Metodologias cualitativas de investigación en comunicación de masas.
Barcelona: Bosch, 1993. 324 p. (Collección Bosch comunicación, 8).

KANT, Emmanuel. Crítica da razão pura. 4. ed. São Paulo: Edições Brasil,1965. 246 p.

KUHN, T. S. A tensão essencial. Lisboa: Edições 70, 1977. 420 p. (Biblioteca de filosofia contemporânea,10).

LADRIÈRE, J. Filosofia e práxis científica. Rio de Janeiro: F. Alves, 1978. 193 p. (Coleção episteme).

MAGEE, B. As idéias de Popper. 3. ed. São Paulo: Cultrix, 1979.

PLATÃO.Diálogos II: Fédon/Sofista/Político. Rio de Janeiro: Ediouro, [198-]. 218 p. (Universidade de bolso, 61272).

. A República. Belém: Universidade

Federal do Pará,1988. 416 p.

Teeteto e Crátilo. Belém : Universidade

Federal do Pará,1988. 177 p.

POPPER, K. A lógica da pesquisa cientifica. 2. ed. São Paulo : Cultrix; 1975.

RITCHIE, J. The contribution of qualitative methods to Social Policy. Survey Methods Newsletter, p. 9-10, winter.1985-1986.

RUBANO, D. R. et al. O caminho para a ciência moderna: da descoberta da razão à descoberta da prática. São Paulo: EDUC,1987. p. 5-12. (Coleção pré-print).

SMITH, K. P. Diversity and direction: the role of qualitative research in information centers. Journal of Education for Library and Information Science, v. 31, n. 2, p. 91-96, 1990.

SOUZA, C. L. de M. Va. A problemática dos métodos quantitativos e qualitativos em Biblioteconomia e Documentação: uma revisão de literatura. Ciência da Informação, Brasília, v.18, n. 2, p.174-182, jul./dez.1989.

SUTTON, B. The rationale for qualitative research: a review of principles and theoretical foundations. Library Quaterly, Chicago, v. 63, n. 4, p. 411-430,1993.

TAYLOR, S. J.; BOGDAN, R. Introducción a los métodos cualitativos de investigación: la búsqueda de significados. Barcelona: Paidós, 1992. 343 p. (Paidós básica, 37).

WEINGAND, D. E. Grounded theory and qualitative methodology. IFLA Journal, v. 19, n. 1, p.17-26, 1993.

WILDEMUTH, B. M. Post-positivism research: two examples of methodological pluralism. Library Quaterly, Chicago, v. 63, n. 4, p. 450-468,1993.

WOLF, M. La investigación de la comunicación de masas. Barcelona: Paidós, 1994. 318 p. 